\title{
DIREITO GLOBAL E RESPONSIVIDADE: UMA ABORDAGEM CRÍTICO-SISTÊMICA DO DIREITO EM FACE DOS NOVOS DESAFIOS DA SOCIEDADE MUNDIAL ${ }^{\mathrm{i}}$
}

\author{
GLOBAL LAW AND RESPONSIVENESS: \\ A CRITICAL-SYSTEMIC APPROACH OF THE \\ LAW FACE THE NEW CHALLENGES OF THE \\ WORLD SOCIETY
}

Douglas Elmauer ${ }^{\mathrm{ii}}$

Sumário: 1 Introdução. 2 Responsividade jurídica: da justiça autossubversiva à crítica imanente do Direito. 3 Direito global e sociedade mundial: diagnósticos, tendências e desafios. 4 Conclusão. Referências.

\begin{abstract}
Resumo
O presente artigo se propõe a dar mais um passo no sentido do desenvolvimento de uma teoria crítica dos sistemas aplicada ao Direito. Visa-se ampliar a teoria sistêmica no sentido de potencializar sua capacidade de diagnosticar os dilemas jurídicos contemporâneos e ao mesmo tempo apontar para o modo de enfrentamento dos desafios existentes numa sociedade mundial paradoxalmente marcada, por um lado, pela ameaça da hipertrofia sistêmica das ordens sociais reificadas e, por outro, pelos processos de constitucionalização que buscam limitar essas ordens.
\end{abstract}

\footnotetext{
${ }^{1}$ Este artigo foi desenvolvido com base em minha Dissertação de Mestrado, defendida na Faculdade de Direito da Universidade de São Paulo (USP) em outubro de 2015. Cf. ELMAUER, Douglas. O direito na teoria crítica dos sistemas: da justiça autossubversiva à crítica imanente do direito. 2015. $316 f$. Dissertação (Mestrado em Direito)-Departamento de Filosofia e Teoria Geral do Direito da Faculdade de Direito da Universidade de São Paulo. São Paulo, SP, 2015. p. 264-281.

${ }^{11}$ Doutorando na Universität Bremen, Alemanha. Bolsista DAAD (Deutsher Akademischer Austauschdienst).
} 
Desse modo, este texto se dividirá em duas partes centrais: a primeira parte trata da explanação da ideia de uma (i) responsividade jurídica obtida por meio da justiça autossubversiva e da crítica imanente do direito como formas de aberturas do sistema jurídico às demandas do ambiente; a segunda parte, debruça-se sobre diagnósticos, tendências e desafios que o (ii) direito global enfrenta na sociedade mundial. O escopo final do artigo se concentra no esforço de construir um direito mais sensível e aberto ao seu próprio ambiente.

Palavras-chave: Teoria crítica dos sistemas. Direito global. Justiça autossubversiva. Sociedade mundial. Responsividade jurídica

\section{Abstract}

This article proposes to take another step towards the development of critical systems theory applied to the law. Seeks to improve the systems theory in order to enhance its capacity to diagnose the contemporary legal dilemmas. At the same time, aiming to face the world society challenges paradoxically marked on the one hand, by the menace of systemic hypertrophy of the reified social orders and on the other, by a constitution processes that seek to limit these orders. Thus, this text will be divided into two main parts: the first part deals with the explanation of the idea of a (i) Legal responsiveness obtained through self-subversive justice and immanent law criticism as forms of the legal system openings to the demands for its environment. The second part, in turn, focuses on diagnostics, trends and challenges that (ii) the global law faces in world society. The final scope of the article focuses on the effort to build a more sensitive and open law to the environment.

Keywords: Critical systems theory. Global Law. Self-subversive justice. World society. Legal responsiveness.

\section{INTRODUÇÃO}

$\mathrm{U}$ ma abordagem crítica da teoria dos sistemas possibilita um estudo mais bem apurado e consequente dos sistemas sociais da sociedade mundial, onde se averigua a hiperexpansividade de racionalidades específicas pertencentes a determinadas ordens sociais. $O$ foco central de uma teoria crítico-sistêmica ${ }^{1}$ é a análise destas ordens sociais as quais se podem denominar "ordens sociais reificadas". Ao desmascarar as discrepâncias e as contradições reais da sociedade mundial, esta teoria crítico-sistêmica permite também trazer à tona a necessidade da regeneração das relações autônomas desta mesma sociedade. Esta demanda por regeneração é especialmente cara ao sistema jurídico quando se analisa a crescente carência de responsividade do direito diante da sociedade mundial, ou seja, de uma justiça ecológica não fetichizada pelo encanto de sua própria racionalidade. A ameaça de um "direito reificado", entendido como manifestação primordial de uma "racionalidade irracional" (Adorno), coloca em xeque (de modo paradoxal) seus próprios logros pela busca infindável e permanentemente variável por justiça. O escopo do presente artigo será precisamente desenvolver e aplicar com maior minúcia este arcabouço conceitual às novas demandas da sociedade mundial para o sistema jurídico.

Diante dos desafios impostos por esta nova realidade, um sistema jurídico mais responsivo e sensível às demandas sociais, capaz de se autotranscender, poderia auxiliar no combate das ordens sociais reificadas (hiperexpansivas) por meio dos processos de constitucionalização dos sistemas da sociedade mundial, hábeis a limitar as dinâmicas reificantes (hipertróficas). É nesses moldes teóricos que a presente argumentação se desenvolverá, com o escopo de utilizar os novos instrumentos oferecidos pela teoria crítica dos sistemas para a análise do sistema jurídico mais responsivo e autolimitado.

\footnotetext{
${ }^{1}$ PHILIPPOPOULOS-MIHALOPOULOS, Andreas. Critical autopoiesis and the materiality of Law. International Journal for Semiotics of Law. Berlin, Springer Science, p. 1-19, 2013; FISCHER-LESCANO, Andreas. Systemtheorie als kritische Gesellschaftstheorie. In: __ ; AMSTUTZ, M. (Hrsg.). Kritische systemtheorie: zur evolution einer normativen theorie. Bielefeld: Transcript Verlag, 2013. p. 13-37. [Versão em português: FISCHER-LESCANO, Andreas. A teoria crítica dos sistemas da Escola de Frankfurt. Revista Novos Estudos. São Paulo, v. 86, p. 163-177, março 2010].
} 


\section{RESPONSIVIDADE JURÍDICA: DA JUSTI- ÇA AUTOSSUBVERSIVA À CRÍTICA IMA- NENTE DO DIREITO}

Com o processo de diferenciação funcional da sociedade, os sistemas sociais não apenas adotaram formas de codificação e de programação próprias, mas também "racionalidades" determinadas, ou como prefere Luhmann, "fórmulas de contingência" específicas. As formas de racionalidades sistêmicas se manifestam, por exemplo, na economia com o problema da "escassez", na política com a questão da "legitimidade", na religião com "Deus", entre outros modos. No sistema jurídico, a "justiça" se coloca como a forma específica de racionalidade (ou fórmula de contingência) do direito.

A justiça dá consistência ao sistema jurídico na busca infindável pelo equilíbrio entre o fechamento operativo (consistência interna) e a abertura cognitiva (adequação social), o que motiva a continuidade das comunicações sistêmicas. ${ }^{2}$ Ao nos referirmos à questão da justiça, devemos esclarecer que se toma como foco a justiça jurídica, a qual não se confunde com a justiça política ou com a justiça moral, por exemplo.

$\mathrm{Na}$ esteira da teoria crítica dos sistemas, a caracterização da justiça jurídica como fórmula de contingência (racionalidade) do sistema jurídico não seria suficiente, antes, ela também seria uma fórmula de transcendência que parte da própria imanência sistêmica. ${ }^{3}$

Para Adorno, o direito é "a manifestação primordial da racionalidade irracional"4, ou seja, de uma racionalidade que pode ser totalitária e expropriante por paradoxalmente promover a injustiça ao mesmo tempo em que faz a justiça.
Sendo assim, ela seria sempre obrigada a se autotranscender com o objetivo de superar esse antagonismo insistente e circular. O direito precisa constantemente recorrer ao seu "arcano interno", a justiça capaz de subverter a si própria e transcender a imanência reificada do sistema jurídico. Todavia, para compreender esses processos sistêmicos é necessário proceder com algumas reconstruções do pensamento adorniano e seguidamente adentrar a ideia de justiça autossubversiva proposta por Teubner.

Adorno criticou insistentemente os conceitos de "consistência" (Strigenz) e de "totalidade" (Totalität) "como ideais burgueses de necessidade e universalidade". ${ }^{5}$ Considerando a totalidade como o não verdadeiro (ou o estado falso), e ao mesmo tempo tomando em consideração a ideia de sistema em seu complexo construto teórico, Adorno procedeu com os primeiros passos para o abandono da tradição do antigo pensamento europeu. Se, por um lado, a teoria dos sistemas se preocupa com as racionalidades autônomas da sociedade, com a diferença básica entre sistema e ambiente e com a coevolução sistêmica, por outro, a teoria adorniana, na linha da "filosofia da nova música" e da "teoria estética", estabelece conceitos que são curiosamente análogos com os da teoria dos sistemas.

"Tanto Adorno como a teoria crítica dos sistemas não concebem o sistema como uma hierarquia estrutural estática”' . Nessa esteira:

A problemática da autonomização foi resumida por Adorno em sua filosofia da música; ele faz a acusação de que a música solipsista, com sua textura rígida, que permite a ela se preservar contra a ubiquidade das operações, tornou-se tão severa que seu elemento trans-

${ }^{2}$ LUHMANN, N. Ausdifferenzierung des rechts: beiträge zur rechtssoziologie und rechtstheorie. Frankfurt: Suhrkamp, 1981. p. 374-418; LUHMANN, N. El derecho de la sociedad. Ciudad de México: Herder, 2005b. p. 275-299 [LUHMANN, N. Das Recht der Gesellschaft. Suhrkamp: Frankfurt am Main, 1993. p. 214-238]. Acerca do tema, ver também NEVES, Marcelo. Transconstitucionalismo. [Tese apresentada ao concurso de provas e títulos para provimento do cargo de professor titular na área de direito constitucional no Departamento de Direito do Estado da Faculdade de Direito da Universidade de São Paulo]. São Paulo, 2009. p 56-58; VILLAS BÔAS FILHO, Orlando. Da ilusão à fórmula de contingência: a justiça em Hans Kelsen e Niklas Luhmann. In: PISSARA, Maria Constança Peres; FABBRINI, Ricardo Nascimento (Coord.). Direito e filosofia: a noção de justiça na história da filosofia. São Paulo: Atlas, 2007. p. 129-150.

${ }^{3}$ TEUBNER, Gunther. Self-subversive justice: contingency or transcendence formula of Law? 2009. Disponível em: <www.uni-frankfurt.de/>. Acesso em: 20 out. 2010. p. 1-22.

4 "Recht ist das Urphänomen irrationaler Rationalität". (ADORNO, T. W. Introdução à sociologia. São Paulo: UNESP, 2007. p. 257 [ADORNO, T. W. Negative dialektik. In: ___ Gesammelte Schriften. Band 6. Frankfurt am Main: Suhrkamp, 1984. p. 304]).

${ }^{5}$ FISCHER-LESCANO, 2013, p. 272010, p. 171. Segundo Adorno: "Stringenz und Totalität, die bürgerlichen Denkideale von Notwendigkeit und Allgemeinheit, umschreiben in der Tat die Formel der Geschichte, aber eben darum schlägt in den festgehaltenen herrschaftlich großen Begriffen die Verfassung der Gesellschaft sich nieder, gegen welche dialektische Kritik und Praxis sich richten" (ADORNO, T. W. Minima moralia: reflexionen aus dem beschädigten Leben. In:__ Gesammelte Schriften. Band 4. Frankfurt am Main: Suhrkamp, 1984. p. 170).

${ }^{6}$ FISCHER-LESCANO, 2013, p. 27 [2010, p. 171] 


\subsection{TEORIA DOS SISTEMAS}

cendente e real - que chegou a dar-lhe o conteúdo que fez a música absoluta verdadeiramente absoluta - é inalcançável.?

Adorno adverte para o fato de que esse fechamento hermético, seja da música ou do sistema, poderia levar a uma espécie de autismo sistêmico capaz de acarretar deficiências, tais como o déficit ou a hipertrofia funcional sistêmica em face do ambiente.

A conclusão de Adorno acerca da arte coincide com o ponto de vista sistêmico do teorema da abertura por meio do fechamento autopoiético, que aqui se torna aplicável para todas as racionalidades sistemicamente diferenciadas, as quais podem apenas existir a partir de uma relação de comensurabilidade com seu ambiente. "Fechamento e abertura simultaneamente: quem está aberto para todas as coisas se torna vazado; ao mesmo tempo, o autismo sistêmico precisa ser evitado"8. "O ponto crucial, segundo argumenta Adorno em sua Teoria Estética, está no fato de a instituição social existir apenas em sua relação com aquilo que ela não é, com seu outro, assim como precisa se manter aberta às influências externas".

Nesse momento teórico, Adorno lança mão do conceito de "fisiognomia" (Physiognomie), a qual diz respeito à relação entre a arte e o seu "exterior" (ambiente). Ao invés de falar na diferença abertura/fechamento, Adorno prefere utilizar a diferença autonomia/heteronomia. Para ele, esse "caráter duplo" (Doppelcharakter) da arte, que na teoria crítica dos sistemas é aplicável a todos os âmbitos sociais sistêmicos, é algo, segundo Adorno:
[...] fisiognomicamente (physiognomisch) decifrável sempre que se ouve ou se contempla a arte exterior, indiferente ao fato de se ela como tal é ou não planificada e, naturalmente, a arte precisa sempre daquele 'do exterior' para ser protegida da fetichização (Fetischisierung) da sua autonomia. ${ }^{10}$

$\mathrm{O}$ excesso de centralidade na dimensão interna do sistema pode levar à fetichização sistêmica, ou seja, ao predomínio de uma imanência reificada que não possui responsividade para com o ambiente. Os âmbitos reificados de racionalidade podem aparecer em todo e qualquer sistema, seja ele a arte, a economia, a política e até mesmo o direito. As noções fetichizadas não são apenas aparências, segundo Adorno, "quando os seres humanos realmente se tornam viciados nessas objetividades opacas, as reificações (Verdinglichungen) não aparecem apenas como falsa consciência (falsches Bewusstsein), mas simultaneamente como realidade". ${ }^{11}$

Considerando essas condições, a teoria crítica dos sistemas busca "ligar novamente as esferas autônomas de racionalidade à realidade - sem a qual aquelas não poderiam existir". ${ }^{12}$ É exatamente essa a proposta de Teubner quando elaborou o conceito de "justiça autossubversiva", ou seja, o conceito de uma justiça com a capacidade de subverter a si mesma, a qual transcenda a imanência reificada do sistema jurídico.

Uma justiça como fórmula de contingência e transcendência - trata-se de "um conceito duplo de justiça, que, como fórmula contingente intrassistêmica, precisa preservar tanto sua consistência interna como sua permeabilidade em relação às demandas vindas da sociedade". ${ }^{13}$ Essa concepção, segundo Fischer-Lescano, tem rele-

\footnotetext{
${ }^{7}$ FISCHER-LESCANO, 2013, p. 27 [2010, p. 171-172]. Para mais detalhes, ver esp. ADORNO, T. W. Gesammelte Schriften. Philosophie der neuen Musik, Band 12. Frankfurt am Main: Suhrkamp, 1984. p. 27.

${ }^{8}$ FISCHER-LESCANO, 2013, p. 28 [2010, p. 172].

${ }^{9}$ FISCHER-LESCANO, 2013, p. 27-28 [2010, p. 172]

${ }^{10}$ ADORNO, 1982, p. 282 [ADORNO, T. W. Ästhetische Theorie. In:

Gesammelte Schriften. Band 7. Frankfurt am Main: Suhrkamp, 1984. p. 375]

No original e na íntegra: "Der Doppelcharakter der Kunst als eines von der empirischen Realität und damit dem gesellschaftlichen Wirkungszusammenhang sich Absondernden, das doch zugleich in die empirische Realität und die gesellschaftlichen Wirkungszusammenhänge hineinfällt, kommt unmittelbar an den ästhetischen Phänomenen zutage. Diese sind beides, ästhetisch und faits sociaux. Sie bedürfen einer gedoppelten Betrachtung, die so wenig unvermittelt in eins zu setzen ist, wie ästhetische Autonomie und Kunst als Gesellschaftliches. Der Doppelcharakter wird physiognomisch lesbar, wann immer man Kunst, gleichgültig, ob sie als solche geplant war oder nicht, von außen sich anhört oder ansieht, und allerdings bedarf sie stets wieder jenes Von außen, um vor der Fetischisierung ihrer Autonomie beschützt zu werden". (ADORNO, 1984, p. 374-375). Para mais detalhes, ver também ADORNO, T. W. Philosophie der neuen Musik. In:_Gesammelte Schriften. Band 12. Frankfurt am Main: Suhrkamp, 1984. p. 158.

${ }^{11}$ FISCHER-LESCANO, 2013, p. 28 [2010, p. 172]

${ }^{12}$ FISCHER-LESCANO, 2013, p. 28 [2010, p. 172]

${ }^{13}$ FISCHER-LESCANO, 2013, p. 28 [2010, p. 172].
} 
vantes implicações normativas, já que "obrigam o direito a buscar traduzir os conflitos estruturais da sociedade em quaestio iuris; a manter mutuamente compatíveis os espaços de autonomia, a garantir condições para a autoconstituição dos indivíduos" ${ }^{14}$

O imperialismo da racionalidade jurídica e sua justiça totalitária (universalizante) tornam o sistema cego para o ambiente, gerando aquilo que é o completamente oposto à justiça almejada: a injustiça. Como expresso no velho brocardo latino de Cícero, summum ius summa injuria ${ }^{15}$, ou seja, o excesso de justiça leva à injustiça, como no exemplo do personagem Michael Kohlhaas, do escritor alemão Kleist. A imanência reificada do direito deve ser combatida com a transcendência. Nesse sentido, "é necessária a abertura a uma referência adicional (Verweisungüberschusses) à ativação de energias utópicas sobre a precondição de injustiças realmente vividas". ${ }^{16}$

A justiça autossubversiva é uma força interna ao direito que se levanta em face do próprio direito; trata-se da "transposição normativa dos limites cognitivos do sistema jurídico na auto-observação (cognitiva)"17, na forma de um transbordamento do marco conceitual da teoria dos sistemas que nesse momento se volta para o "outro" (no sentido de Lévinas e Derrida), sendo por isso, também, uma justiça responsiva (ecológica).

O conceito de justiça em Luhmann está baseado na ideia de fórmula de contingência (interna e formal) fundada na proibição da negação, na canonização, que ao mesmo tempo traz consigo o paradoxo de sua constante busca pelo irrefutável, o que leva sempre à criação de novas contingências. ${ }^{18}$ Para Teubner, falta no conceito luhmanniano a ideia de justiça como transcendência, não apenas contingência, já que em torno dela sempre se abre um "espaço imaginário" no qual se podem criar "ficções sobre o mundo exterior"; são as "energias utópicas" presentes no sistema jurídico. ${ }^{19}$

\begin{abstract}
A justiça atua internamente ao direito como uma força subversiva, com a qual o direito protesta contra si mesmo. A justiça protesta contra as tendências naturais do direito de se vincular a precedentes, rotina, segurança, estabilidade, autoridade e tradição. Contra as tendências de autocontinuidade bem ordenada embutidas no direito, a justiça exibe sua preferência pela desordem, revolta, divergência, variabilidade e mudança. Ela protesta em nome da sociedade, dos homens e da natureza - entretanto, ela o faz a partir do arcano interno do direito. A justiça subversiva é o espinho na carne. 'Motim a bordo' (Mauterei auf der Bounty) - é este o recado da sociologia para a justiça jurídica. ${ }^{20}$
\end{abstract}

De modo pertinente, Brunkhorst observa que esse poder da justiça autossubversiva é o que também está presente nas grandes revoluções jurídicas e constitucionais da sociedade na forma de um "aprendizado normativo" - trata-se da transformação da injustiça em justiça pela autotranscendência revolucionária, a alteração do status quo pelo direito. ${ }^{21}$

As implicações que a mudança de compreensão da ideia de justiça traz ao sistema jurídico são profundas. O direito passa a ser responsabilizado pelas injustiças por ele mesmo criadas, ou seja, pela sua "racionalidade irracional" (Adorno). No momento em que se reconhece a incapacidade do direito em realizar a justiça, emerge também o "motim" em sua interioridade. Trata-se de uma espécie de resistência que deriva de seu próprio "arcano interno".22

\footnotetext{
${ }^{14}$ FISCHER-LESCANO, 2013, p. 29 [2010, p. 172].

${ }^{15}$ CÍCERO, Marcus Tullius. De Officiis. Translated by Walter Miller. Loeb edn. Cambridge: Harvard University Press, 1913. p. 33-34 (Livro I, X, 33).

${ }^{16}$ FISCHER-LESCANO, 2013, p. 29 [2010, p. 173]. Para mais detalhes acerca da ideia da "ativação de energias utópicas" por meio da justiça, ver TEUBNER, G. Dealing with paradoxes of law: Derrida, Luhmann, Wiethölter. In: Publishing, 2006a. p. 54.

${ }^{17}$ BRUNKHORST, H. Ilusões de factibilidade, declarações festivas e cantorias: sobre a relação entre evolução e revolução no Direito. Civitas. Porto Alegre, v. 9, n. 3, p. 440-458, 2009. p. 442.

${ }^{18}$ TEUBNER, Gunther. Justiça autosubversiva: fórmula de contingência ou de transcendência do Direito? Revista Eletrônica do Curso de Direito, PUC Minas Serro [Online], 0.4, p. 17-54, 2011b. p. 27 [TEUBNER, Gunther. Self-subversive justice: contingency or transcendence formula of law? 2009a. p. 1-22. Disponível em: <www.uni-frankfurt.de/>. Acesso em: 20 out. 2010. p. 8].

${ }^{19}$ TEUBNER, 2011b, p. 31 [2009a, p. 11].

${ }^{20}$ TEUBNER, 2011b, p. 32-33 [2009a, p. 12].

${ }^{21}$ Cf. BRUNKHORST, 2009, p. 443, 455.

${ }^{22}$ Cf. TEUBNER, 2011b, p. 33 [2009a, p. 12]
} 


\subsection{TEORIA DOS SISTEMAS}

A autodescrição do sistema jurídico por meio da justiça é em si mesma paradoxal já que a continuidade da circularidade recursal das operações jurídicas sempre leva à geração de novas injustiças, como no trilema de Münchhausen, numa constante oscilação agonizante. Essa autossabotagem sistêmica conduz sempre à conclusão de que ao ser produzida a injustiça, "a justiça deve novamente protestar, para então se expor mais uma vez aos compelimentos do sistema jurídico". ${ }^{23}$ A dinâmica da autossubversão é uma forma de circularidade entre as decisões jurídicas positivas (imanência) e o protesto pela justiça (transcendência), ou seja, "a práxis realiza e impossibilita a justiça em uma transformação permanente da imanência à transcendência do direito e de volta à imanência" ${ }^{24} \mathrm{O}$ conceito de transcendência da justiça, importado por Teubner do pensamento de Derrida, ${ }^{25}$ não implica adjudicação de critérios externos ao sistema, ou seja:

Os critérios da justiça não são, então, encontrados em algum lugar fora do direito, antes, o direito só pode se autotranscender de forma tal que ele se diferencie de si mesmo, na reentrada autoproduzida, aqueles ambientes dos quais o conflito jurídico se origina - sociedade, natureza, homem, para, então, em relação a essas enacted ecologies, estabelecer critérios de justiça ambientalmente adequados. ${ }^{26}$

Se o direito é excludente em seu aspecto decisório, o papel da justiça é exatamente o de reclamar a inclusão daquilo que ficou excluído desse processo, o "inteiramente outro". Como colocaria Derrida em suas analogias rabínicas, essa experiência de transcendência pela justiça é a "travessia do deserto" feita pelos cativos injustiçados. Se em Luhmann a transcendência está presente apenas no sistema religioso, para Derrida essa experiência pode ser estendida a toda a sociedade, incluindo os mundos autônomos altamente racionalizados, tais como a economia, a ciência, a política e o direito. ${ }^{27}$

No sistema jurídico, a justiça desempenha essa função, que impele o direito para além da limitação de suas fronteiras - "o discurso da justiça começa onde o direito termina"28 - "a justiça deve ultrapassar o direito em cada sentido, realizar a experiência da transcendência específica do direito, sob cuja impressão ela deve retornar para a imanência do direito". ${ }^{29}$ A justiça como princípio dinâmico do sistema jurídico, possibilita a superação da fratura entre imanência e transcendência, num constante processo de transformação do ilícito em lícito. Nesse sentido, "a justiça apenas se torna possível com a passagem real pela injustiça", como ocorre nos processos sociais de colère publique (Durkheim) ou com os argumentos sustentados pelo terror em face dos "corpos torturáveis" (Adorno). ${ }^{30}$

A articulação das experiências de injustiça já havia sido abordada por Adorno ao tratar do fenômeno da "imediaticidade social" (gesellschaftlicher Unmittelbarkeit). ${ }^{31}$

A imediaticidade social existe somente em configurações que não transformam a justiça em organizações jurídicas. Ao mesmo tempo, e aqui se nota seu momento dialético, a condição para que a fórmula transcendente tenha efeito é que a operação estabelecida e praticada pelo direito exista no mundo. ${ }^{32}$

Portanto, trata-se da interdependência mútua entre imanência e transcendência, ou como diria Sonja Buckel, entre "proteção" (Schutz) e "farsa" (Maskerade). ${ }^{33}$

Adorno, na esteira da "dialética negativa" e da

\footnotetext{
${ }^{23}$ TEUBNER, 2011b, p. 35 [2009a, p. 13].

${ }^{24}$ TEUBNER, 2011b, p. 35 [2009a, p. 14]

${ }^{25}$ Cf. DERRIDA, Jacques. Força de lei: o fundamento místico da autoridade. São Paulo: Martins Fontes, 2007. p. 41 e ss.

${ }^{26}$ TEUBNER, 2011b, p. 39 [2009, p. 15-16].

${ }^{27}$ TEUBNER, 2011b, p. 40 [2009, p. 16].

${ }^{28}$ TEUBNER, 2011b, p. 41 [2009, p. 17].

${ }^{29}$ TEUBNER, 2011b, p. 42 [2009, p. 18].

${ }^{30}$ Cf. FISCHER-LESCANO, 2013, p. 29 [2010, p. 173]; TEUBNER, 2011b, p. 43 [2009, p. 18]. Para mais detalhes acerca da apropriação do conceito de colère publique na teoria dos sistemas, ver, esp. FISCHER-LESCANO, Andreas. Ex facto ius oritur: procesos de escándalo y el derecho mundial emergente. DOXA - Cadernos de Filosofia del Derecho, Alicante, v. 30, p. 435-450, 2007. Sobre a ideia de "corpos torturáveis", ver, esp. ADORNO, ADORNO, T. W. Negative Dialektik. In:___. Gesammelte Schriften. Band 6. Frankfurt am Main: Suhrkamp, 1984, 6, p. 281 [2009, p. 238].

${ }^{31}$ Cf. ADORNO, 1984, 6, p. 281 [2009, p. 238].

${ }^{32}$ FISCHER-LESCANO, 2013, p. 29 [2010, p. 173].
} 


\subsection{TEORIA DOS SISTEMAS}

“justiça restauradora” ${ }^{34}$, mostra que essa interdependência também está presente no "princípio da troca". Segundo ele, "o que a crítica ao princípio da troca deseja é que o ideal da troca livre e justa, até hoje um mero pretexto, se torne realidade. Apenas isso transcenderia a troca" ${ }^{35}$ Do mesmo modo, Teubner pensa essa mesma função para a justiça jurídica diante da imanência reificada do direito e suas injustiças.

Decorre dessa postura de pensamento uma espécie de crítica imanente do direito como uma atitude de transcendência. Pode-se definir a crítica, em poucas palavras, como uma atitude específica com relação ao mundo ${ }^{36}$ - a crítica do status quo (Horkheimer). ${ }^{37}$

Horkheimer e Adorno definem com mais precisão o que diferencia a "sociologia descritiva" da "teoria crítica da sociedade", considerando que "a sociologia se converte em crítica da sociedade no mesmo momento em que não se limita a descrever e ponderar as instituições e os processos sociais, mas sim quando os confronta com esse substrato", trazendo à tona os conflitos e os antagonismos que marcam as tensões reais das relações entre a vida e as instituições. ${ }^{38}$

Seguindo os moldes do teor imanente da teoria crítica da sociedade de Adorno e Horkheimer, "a teoria crítica dos sistemas não é uma mera tecnologia social, nem uma descrição sociológica extrínseca, nem autodescrição teórico-jurídica, mas um esforço eminentemente filosófico de crítica social”. ${ }^{39}$ Essa crítica se torna possível no marco sistêmico-teórico a partir do momento em que se considera a existência de um referencial transcendente que transborda da própria imanência. De acordo com Fischer-Lescano, seguindo Adorno nesse ponto, "é no arcanum da sociedade, na atitude, no ponto de vista da resistência que a faculdade de distinguir o reconhecível e o meramente convencional, ou o que está sob a coerção da autoridade vigente, surge como crítica, que é derivada do termo grego krino, decidir" ${ }^{40}$

Todavia, é um pressuposto fundamental da teoria crítica dos sistemas que a sociedade não possa ser descrita a partir de fora. Nesse sentido, toda e qualquer forma de crítica deve ser necessariamente imanente, ou seja, deve partir de dentro do próprio sistema. A crítica imanente é sempre baseada nas próprias discrepâncias produzidas na interioridade do sistema. ${ }^{41}$ Por isso a teoria crítica dos sistemas busca analisar o direito das sociedades reais, em seus antagonismos constitutivos, tematizando as contradições fundamentais da sociedade. Na esteira das análises de Menke, o direito se justifica por meio de seus próprios antagonismos. ${ }^{42}$ Segundo ele, a forma jurídica e a produção dessa forma guardam consigo um aspecto de normatividade, no qual "o poder ( Kraft), de cuja expansão emerge a forma, é ao mesmo tempo uma exigência que se volta contra a própria forma que emerge. Essa exigência requer que a forma corresponda ao seu outro, que lhe faça justiça" ${ }^{43}$ - ou seja, trata-se da co-

\footnotetext{
${ }^{33}$ BUCKEL, Sonja. Zwischen Schutz und Maskerade: Kritik(en) des Rechts. Informationsbrief. Aufgabe 102, p. 11-23, Rav Infobrief, august 2009. p. 11 e ss.

${ }^{34}$ Cf. HONNETH, Axel. Pathologies of reason: on the legacy of critical theory. New York: Columbia University Press, 2009. p. 87.

${ }^{35}$ Citado em FISCHER-LESCANO, 2013, p. 29 [2010, p. 173]. Para mais detalhes, ver ADORNO, 1984, 6, p. 150 [2009, p. 128]. No original e na íntegra: "Annullierte man simpel die Maßkategorie der Vergleichbarkeit, so träten anstelle der Rationalität, die ideologisch zwar, doch auch als Versprechen dem Tauschprinzip innewohnt, unmittelbare Aneignung, Gewalt, heutzutage: nacktes Privileg von Monopolen und Cliquen. Kritik am Tauschprinzip als dem identifizierenden des Denkens will, daß das Ideal freien und gerechten Tauschs, bis heute bloß Vorwand, verwirklicht werde. Das allein transzendierte den Tausch." (ADORNO, 1984, 6, p. 150).

${ }^{36}$ Cf. FISCHER-LESCANO, 2013, p. 31 [2010, p. 173]. Ver, esp, FOUCAULT, Michel. O que é a crítica? 1978. Disponível em: <www.filoesco.unb.br/ foucault>. Acesso em: 12 jan. 2011.p. 1-2; SANTOS, Boaventura Sousa. "Por que é tão difícil construir uma teoria crítica?" Revista Crítica das Ciências Sociais, Coimbra, n. 54, p. 197-215, jun. 1999.

${ }^{37}$ Cf. HORKHEIMER, Max. Teoría tradicional y teoría crítica. In: (Org.). Teoría crítica. Buenos Aires: Amorrortu, 2003. p. 259

${ }^{38}$ ADORNO T. W.; HORKHEIMER, M. La sociedad: lecciones de sociología. Buenos Aires: Proteo, 1969. p. 32.

${ }^{39}$ FISCHER-LESCANO, 2013, p. 31 [2010, p. 174].

${ }^{40}$ FISCHER-LESCANO, 2013, p. 31 [2010, p. 174]. Para mais detalhes, ver esp. ADORNO, ADORNO, T. W. Kritik. In: (Ed.) Gesammelte Schriften. Band 10. Frankfurt am Main: Suhrkamp, 1984, 10, p. 785-793. No original: "Solcher Widerstand, als Vermögen der Unterscheidung des Erkannten und des bloß konventionell oder unter Autoritätszwang Hingenommenen, ist eins mit Kritik, deren Begriff ja vom griechischen krino, Entscheiden, herrührt." (ADORNO, 1984, 10, p. 785)

${ }^{41}$ FISCHER-LESCANO, 2013, p. 31 [2010, p. 174].

${ }^{42}$ Cf. MENKE, Christoph. Subjektive rechte: zur paradoxie der form. Zeitschrift für Rechtssoziologie. Stuttgart, v. 29, 2008, p. 105.

${ }^{43}$ MENKE, 2008, p. 105. Reproduzindo e apropriando essa análise, ver FISCHER-LESCANO, 2013, p. 32 [2010, p. 174].
} 


\subsection{TEORIA DOS SISTEMAS}

produção da forma e de sua oposição, como no conceito teubneriano de justiça autossubversiva.

Retraduzindo o movimento descrito por Menke, Fischer-Lescano argumenta que:

\begin{abstract}
A teoria crítica dos sistemas integra em sua crítica do direito essas exigências normativas que no direito se voltam contra o próprio direito de forma paradoxal e o leva a transcender a si mesmo num permanente tornar-se justiça do outro. Em sua busca por justiça, a teoria crítica dos sistemas argumenta com e por meio do direito e se submete às constrições sistêmicas de sentido para logo livrar-se delas e contribuir para quebrar o encanto do fechamento sistêmico. ${ }^{44}$
\end{abstract}

A ideia de "quebrar o encanto" do fechamento, ou melhor, de desfetichizar o sistema autista de sua imanência reificada, justifica-se na medida em que o sistema é sempre um sistema na sociedade, coexistindo com outros sistemas. $\mathrm{O}$ sistema cegado por sua própria interioridade perde a capacidade de reagir adequadamente ao ambiente, ou seja, deixa de ser responsivo. Parafraseando Adorno, pode-se dizer que aquilo que o próprio sistema fetichizado "possui de total exerce um encanto, que apesar de toda afetação afirmativa, torna-se nulo ante a desgraça real" ${ }^{45}$, e no caso do sistema jurídico, isso se torna evidente diante das injustiças reais que se derivam de uma ordem jurídica reificada.

Partindo dessas averiguações, a teoria crítica dos sistemas busca promover uma ciência jurídica "socialmente adequada" e "sociologicamente informada", especialmente num cenário de surgimento de novas perspectivas jurídicas proporcionadas pela "colisão de regimes", redes transnacionais, conflitos de princípios organizacionais, entre outros modos possíveis de manifestação do direito neoespontâneo.

Nessas condições, Fischer-Lescano considera que dois pontos parecem significativos para o direito, sendo eles (i) a "crítica dos valores"
(Wertkritik) e (ii) a "crítica ao estatismo" (Etatismuskritik). ${ }^{46}$

$\mathrm{Na}$ via da "crítica dos valores" (Wertkritik), segundo Fischer-Lescano:

A reformulação jurídica dos conflitos sociais em torno da estrutura social e de questões distributivas em termos de construções sofisticadas de valores e princípios, sobre os quais se poderia chegar a um acordo prático, consiste na tentativa inadequada e de caráter autoritário de solucionar os conflitos sociais do século $\mathrm{XXI}^{47}$

Assim, o caminho mais adequado às configurações da sociedade moderna estaria na criação de precondições para a segurança mútua dos diversos espaços autônomos da sociedade, tais como as "esferas espontâneas" 48 , capazes de possibilitar a autorregulação social.

No mesmo sentido, a "crítica ao estatismo" (Etatismuskritik) busca demonstrar que a política deixou de ser a única esfera social que se usurpa dos espaços sociais de autonomia. Atualmente, as tendências expansionistas turboautopoiéticas estão presentes em muitos sistemas funcionais ${ }^{49}$, podendo manifestar-se da economicização, da juridificação, da midialização, da medicinização, entre outros modos, que implicam "riscos específicos, que precisam ser combatidos pela introdução da obrigação de se agir de modo responsivo em relação ao ambiente social (seres humanos, sistemas e ecossistema natural)". ${ }^{50}$ Nesse ponto, a teoria crítica dos sistemas se une à tese de Habermas acerca da "colonização do mundo da vida" (Kolonialisierung der Lebenswelt), a qual denuncia a nociva expansividade dos sistemas administrativo e econômico. ${ }^{51}$

A "crítica dos valores" (Wertkritik) e a "crítica ao estatismo" (Etatismuskritik) traduzem "a teoria crítica dos sistemas para contra-modelos concretos com os quais pode intervir nas lutas pela adequação social das leis existentes". ${ }^{22}$ Con-

\footnotetext{
${ }^{44}$ FISCHER-LESCANO, 2013, p. 32 [2010, p. 174].

${ }^{45}$ ADORNO, T. W. Dialética negativa. Rio de Janeiro: Zahar, 2009. p. 312 [1984, 6, p. 369]. No original: "Das Totale der Frage selbst übt einen Bann aus, der bei allem affirmativen Gehabe nichtig wird vorm realen Unheil." No mesmo sentido, ver FISCHER-LESCANO, 2013, p. 32 [2010, p. 174].

${ }^{46}$ Cf. FISCHER-LESCANO, 2013, p. 32-33 [2010, p. 175].

${ }^{47}$ FISCHER-LESCANO, 2013, p. 32-33 [2010, p. 175].

${ }^{48}$ Cf. TEUBNER, Gunther. Constitutional fragments: societal constitutionalism and globalization. Oxford: Oxford University Press, 2012 . p. 89 e ss.

${ }^{49}$ Cf. TEUBNER, 2012a, p. 79.

${ }^{50}$ FISCHER-LESCANO, 2013, p. 33 [2010, p. 175].

${ }^{51}$ Cf. HABERMAS, Jürgen. Teoría de la accion comunicativa. Buenos Aires: Taurus, 1999. v. II. p. 451 e ss.
} 


\subsection{TEORIA DOS SISTEMAS}

siderando, junto com Adorno, que "o todo é o não verdadeiro" (das Ganze ist das Unwahre) ( $^{53}$, "quem quer introduzir caos na ordem precisa forçar o sistema de dentro para fora para com isso jogar a faísca nessa lareira que pode fazê-la explodir"54 - é o "espinho na carne", o "motim a bordo" "55, a revolução ${ }^{56}$, ou seja, trata-se do movimento autotranscendente do sistema jurídico, o qual é ao mesmo tempo uma crítica imanente. Brunkhorst, inspirado no conceito de justiça autossubversiva de Teubner, afirma que esse direito "não cumpre apenas a função de estabilização de expectativas, ele não é apenas sistema imunológico da sociedade (Luhmann), mas é ao mesmo tempo medium da práxis transformadora do mundo" ${ }^{57}$ que clama em face das injustiças realmente vividas.

\section{DIREITO GLOBAL E SOCIEDADE MUN- DIAL: DIAGNÓSTICOS, TENDÊNCIAS E DESAFIOS}

\section{Relatam Fischer-Lescano e Teubner que:}

Em 1971, enquanto teorizava sobre o conceito de 'sociedade mundial' [Weltgesellschaft], Luhmann permitiu-se elaborar a hipótese especulativa de que o direito global iria experimentar uma radical fragmentação, não no âmbito territorial, mas conforme distinções setoriais da sociedade. ${ }^{58}$

Em seus escritos, que precedem o giro teórico autopoiético, Luhmann admite que no plano estrutural da sociedade mundial os sistemas primariamente orientados cognitivamente, como economia, ciência e técnica, ganhariam certa primazia no processo de mundialização, enquanto os sistemas orientados normativamente, como a política e o direito, encontrariam dificuldades e limitações para alçar um nível global. ${ }^{59}$ Esse descompasso entre a evolução das estruturas cognitivas e normativas é, em certa medida, um dos pontos mais sensíveis de uma análise da sociedade moderna e, por isso, traz consigo o desafio de como seria possível o estabelecimento de estruturas normativas no plano da sociedade mundial.

A teoria crítica dos sistemas surge no contexto da sociedade mundial, embebida nesses complexos antagonismos e nessas discrepâncias. Certamente, o século XXI é um período de complexos desafios para o sistema jurídico, bem como para uma teoria preocupada com as estruturas normativas da sociedade.

As tendências sistêmicas expansivas têm gerado uma cadeia infindável de externalidades negativas, que vão desde a perda da autonomia funcional de alguns subsistemas, até a exclusão massiva de pessoas ao acesso às prestações sistêmicas básicas. ${ }^{60}$ Nesse processo tendenciosamente autodestrutivo da sociedade global, Brunkhorst destaca três mazelas: (1) a hipertrofia do sistema econômico e o excesso de pró-ciclici-

\footnotetext{
${ }^{52}$ FISCHER-LESCANO, 2013, p. 33 [2010, p. 175].

${ }^{53}$ ADORNO, T. W. Minima moralia: reflexões a partir da vida lesada. Rio de Janeiro: Azougue, 2008. p. 46 [ADORNO, T. W. Minima Moralia: Reflexionen aus dem beschädigten Leben. In: ___ Gesammelte Schriften. Band 4. Frankfurt am Main: Suhrkamp, 1984, 4, p. 55]. Também, ver ADORNO, T. W. Hegel: three studies. Cambridge: MIT, 1993. p. 87 [ADORNO, T. W. Drei Studien zu Hegel. In:___. Gesammelte Schriften. Band 5. Frankfurt am Main: Suhrkamp, 1984, 5, p. 324].

${ }^{54}$ FISCHER-LESCANO, 2013, p. 33 [2010, p. 175]. Ver também TEUBNER, 2011, p. 36 [2009a, p.14].

${ }^{55}$ Cf. TEUBNER, 2011b, p. 32-33 [2009a, p. 12].

${ }^{56}$ Cf. BRUNKHORST, 2009, p. 443.

${ }^{57}$ BRUNKHORST, 2009, p. 447. Sobre a ideia do Direito como sistema imunológico da sociedade, ver esp. LUHMANN, 2005 , p. 642 e ss. [1993, p. 565 e ss.]. Para uma análise crítica acerca do conceito de direito como sistema imunológico, ver esp. GUERRA FILHO, Willis Santiago. Luhmann and Derrida: immunology and autopoiesis. In: LA COUR, Anders; PHILIPPOPOULOS-MIHALOPOULOS, Andreas (Org.). Luhmann observed: radical theoretical encounters. Londres: Palgrave Macmillan, 2013. p. 227 e ss.

${ }^{58}$ FISCHER-LESCANO, Andreas; TEUBNER, Gunther. Colisões de regimes - a busca vã por unidade jurídica na fragmentação do direito global. Revista Brasileira de Estudos Constitucionais - RBEC. Belo Horizonte, ano 6, n. 21, p.105-155, jan./mar. 2012, p. 105 [TEUBNER; FISCHER-LESCANO. Regimme-collision. The vain search for legal unity in the fragmentation of global law. Michigan Journal of International Law. Michigan, v. 25, 2004. p. 1.000]. Ainda sobre o tema da hodierna estrutura do Direito Global, Larry Catá Backer fala em quatro características inerentes a essa nova configuração do sistema jurídico: fragmentação, fluidez, permeabilidade e policentricidade. Cf. BACKER, Larry Catá. The structure of global law: fracture, fluidity, permeability and polycentricity. CPE Working Papers n. 2012-7, Carlisle, Penn State Law, Research Paper n. 15-2012, p. 102-122 (esp. p. 106). Para mais detalhes sobre a hipótese especulativa de Luhmann, ver esp. LUHMANN, N. Sociologia do direito. Rio de Janeiro: Tempo Brasileiro, 1983. v. II. p. 154 e ss. Sobre a emergência da "sociedade mundial", ver esp. STICHWEH, Rudolf. On the genesis of world society: innovations and mechanisms. 2000. Disponível em: <http://www.uni-bielefeld.de/(en)/soz/iw/pdf/stichweh_2.pdf>. Acesso em: 20 ago. 2012. Sobre a emergência de um Direito Transnacional, ver ZUMBANSEN, Peer. Transnational law. In: SMITS, Jan (Ed.). Encyclopedia of comparative law. Northampton: Edward Elgar Publishing, 2006. p. 738-754. ${ }^{59}$ LUHMANN, N. Die Weltgesellschaft. Soziologische Aufklärung 2: Aufsätze zur theorie der Gesellschaft. Opladen: Westdeutscher Verlag, p. 51-71, 1975. p. 55; LUHMANN, N. Evolution und Geschichte. Soziologische Aufklärung 2: Aufsätze zur theorie der Gesellschaft. Opladen: Westdeutscher Verlag, p. 150-69, 1976. p. 154; LUHMANN, 1981, p. 150.
} 


\subsection{TEORIA DOS SISTEMAS}

dade financeira, que desembocaram na recente crise de $2008^{61}$, derivada da livre e incontrolável dinâmica do capitalismo internacional, o qual vem desmantelando progressivamente as fronteiras nacionais, bem como o direito vinculado aos Estados, inclusive os direitos fundamentais. Em suas palavras, "o capitalismo é global, um sistema altamente produtivo, mas internamente catastrófico, que de modo algum precisa da democracia e para o qual, infelizmente, não existe atualmente qualquer alternativa". ${ }^{2}$ Outra mazela seria o (2) "fundamentalismo religioso", que se transnacionalizou e hoje ameaça conquistas fundamentais da modernidade ${ }^{63}$, inclusive os espaços sociais de liberdade em diversas partes do mundo - o exemplo mais evidente dessa realidade é o "Estado Islâmico" (ISIS), com sua megalomaníaca pretensão de reestabelecer os califados do medievo -; por fim, também (3) a expansividade dos processos de poder e do direito hegemônico ${ }^{64}$ no plano mundial, que ameaça igualmente a manutenção da sociedade moderna e de sua diferenciação funcional, pois corrompe a autonomia dos múltiplos âmbitos sociais. ${ }^{65}$

Revela-se desse modo o "lado sombrio" (dark side) da sociedade moderna ${ }^{66}$ - trata-se do paradoxo da diferenciação funcional. A diferenciação da sociedade em subsistemas funcionais (dentro de suas dinâmicas hiperexpansivas) passou a ameaçar paradoxalmente a própria manutenção da sociedade que ela mesma possibilitou outrora. Tem-se então aquilo que Brunkhorst identificou como o retorno da dialética do esclarecimento na sociedade mundial. ${ }^{67}$ Em consonância com Brunkhorst, Neves destaca que a "autonomia operacional dos sistemas sociais parciais, embora constitua uma exigência funcional, não se realiza em grande parte do globo terrestre e, portanto, prejudica a diferenciação funcional no plano global". 68 Trata-se aqui do problema da "corrupção sistêmica" que leva à "sabotagem de códigos" ${ }^{69}$ Neves identifica essa condição da sociedade mundial como uma verdadeira "patologia da normalidade" (pathology normalcy) ${ }^{70}$, recuperando neste ponto um termo do pensador frankfurtiano Erich Fromm, para expres-

\footnotetext{
${ }^{60}$ Acerca da questão da exclusão na ótica sistêmica, e seus desdobramentos, ver esp. LUHMANN, N. Inklusion und exklusion. Soziologische Aufklärung 6: Die soziologie und der Menschen. Opladen: Westdeutscher Verlag, p. 237-264, 1994. p. 237-264 [1998, p. 167-195] e LUHMANN, N. Gesellschaftsstruktur und semantik. Studien zur wissenssoziologie der modernen Gesellschaft. Frankfurt: Suhrkamp, v. 4. p. 138-150, 1995. p. 138-150. Para ver a definição de inclusão em Luhmann, ver esp. LUHMANN, N. La sociedad de la sociedad. Ciudad de México: Herder, 2007. p. 48. Seguindo, em grande medida Rudolf Stichweh, Teubner se questiona sobre a possibilidade de a diferença inclusão/exclusão se converter no metacódigo do século XXI, que mediatizaria todos os demais códigos binários dos subsistemas sociais na sociedade moderna funcionalmente diferenciada. Sobre as "cadeias de exclusão", ver esp. LUHMANN, N. Die politik der Gesellschaft. Frankfurt am Main: Suhrkamp, 2000. p. 427. Para mais detalhes, ver esp. TEUBNER, G. La constitucionalización de la sociedad global. In: Carlos Gómez-Jara Díez (Ed.) El derecho como sistema autopoiético de la sociedad global. Lima: ARA Editores. p. 69-111, 2005b. p. 72-73. Para um estudo específico sobre a diferença inclusão/exclusão na teoria dos sistemas, ver STICHWEH, Rudolf. Inklusion/exklusion, funk tionale differenzierung und die theorie der Weltgesellschaft. Soziale Systeme Heft 3. p. 123-136, 1997. p. 244 e ss.; BACHUR, João Paulo. Inclusão e exclusão na teoria dos sistemas sociais: um balanço crítico. BIB. São Paulo, n. 73, p. 55-83, $1^{\circ}$ semestre de 2012. p. 55-83.

${ }^{61}$ Sobre o conceito de "crise" como "curto circuito" na reprodução autopoiética, ver esp. KJÆR, Poul. Law and order within and beyond national configurations. 2010. Disponível em: <papers.ssrn.com/sol3/papers.cfm?abstract_id=1687013>. Acesso em: 12 jan. 2013.p. 4.

${ }^{62}$ BRUNKHORST, H. Rumo a uma nova ordem global: vinte anos após 1989 e além. RBCS. São Paulo, v. 26, n. 77, p. 25-30, outubro 2011. p. 28. Acerca do tema, ver também, TEUBNER Gunther; GRABER, Christoph B. Art and money: constitutional rights in the private sphere? Oxford Journal of Legal Studies. Oxford, v. 18, n. 1, p. 61-73, 1998.; TEUBNER, 2011, p. 9-51. Sobre a ideia de bloqueios e corrupção sistêmica, ver NEVES, Marcelo. Niklas Luhmann: eu vejo o que tu não vês. In: ALMEIDA, Jorge de; BADER, Wolfgang (Org.). Pensamento alemão no século XX: grandes protagonistas e recepção da obra no Brasil. São Paulo: Cosac Naify; Instituto Goethe de São Paulo, 2013. p. 341. Sobre a expansividade da economia, também no âmbito da dogmática jurídica e teoria do direito, ver esp. NEVES, Marcelo. Pesquisa interdisciplinar no Brasil: o paradoxo da interdisciplinariedade. In: Crítica à dogmática: dos bancos acadêmicos à prática dos tribunais. Porto Alegre: Instituto de hermenêutica Jurídica, 2005. p. 207 e ss. Ver também, CAMPILONGO, Celso F. O direito na sociedade complexa. São Paulo: Max Limonad, 2000. p. 118

${ }^{63}$ Cf. ŽIŽEK, Slavoj Unsere Trägheit ist die größte Gefahr“. Der Spiegel, Heft 12, 14, p. 130-134, märz 2015.

${ }^{64}$ Sobre a ideia de "direito hegemônico", ver BRUNKHORST, H. Solidarity: from civic friendship to a global level community. Cambridge: MIT Press, 2005. p. 127 e ss. e BUCKEL, Sonja; FISCHER-LESCANO, Andreas. Reconsiderando Gramsci: hegemonia no direito global. Revista Direito GV, São Paulo, 5(2), p. 471-490, jul.-dez. 2009. p. 482-483. Na tradição da interpretação marxista do direito burguês, Paschukanis fala no "direito do mais forte" (Faustrecht). Cf. PASCHUKANIS, Evgeni. A teoria geral do direito e o marxismo. Coimbra: Centelha, 1977, p. 169 e ss.

${ }^{65} \mathrm{Cf}$. BRUNKHORST, H. Democracy under pressure: the return of the Dialectics of Enlightenment in the world society. Civitas. Porto Alegre, v. 10, n. 1, p. 153-171, jan.-abr. 2010. p. 164 e ss.

${ }^{66}$ Cf. BRUNKHORST, 2005, p. 113.

${ }^{67}$ Cf. BRUNKHORST, 2010, p. 154 e ss. Neves chega a uma conclusão semelhante, mas enfatiza a questão da metadiferença inclusão/exclusão como fator que leva ao desmantelamento da diferenciação funcional. Para tanto ver, NEVES, 2013, p. 348; LUHMANN, N. Das Recht der Gesellschaft. Suhrkamp: Frankfurt am Main, 1993. p. 583 [2005, p. 661].

${ }^{68}$ NEVES, 2013, p. 342.

${ }^{69}$ Cf. NEVES, 2009, p. 39, 262.

${ }^{70}$ Cf. FROMM, Erich. The sane society. London: Routledge, 2008. p. 12 e ss.
} 
sar a forma danosa e autodestrutiva com que os sistemas sociais se relacionam entre si e com a sociedade (como um sistema mais abrangente), impossibilitando a realização de uma série de acoplamentos estruturais, prestações e execução da própria função sistêmica específica de modo "saudável" (autônomo e autolimitado).

Nesse cenário, a teoria crítica dos sistemas busca meios para combater essas ordens sociais reificadas, fetichizadas, hipertróficas, que ameaçam a diferenciação funcional da sociedade moderna e seus espaços de liberdade. Ela não logra isso por meio de um sistema político mundial, como se tudo pudesse ser resolvido por meio de um mundo republicanizado. Em face dessa postura, para a teoria crítica dos sistemas, "a política como sistema, esse fetiche da coletivização, é ópio para o povo, e equivale à institucionalização de uma fantasmagoria e uma declaração irrealizável de autossuficiência. Em vez disso, a utopia é uma sociedade civil (jurídica) mundial sem o Estado" 71 , como a nova Pax bukowina de Teubner ${ }^{72}$, em analogia com a "associação de homens livres" (Verein freier Menschen) de Marx. ${ }^{73}$

Um sistema jurídico responsivo, em sua crítica imanente, lidaria com a nova realidade da sociedade mundial por meio de uma perspectiva crítico-emancipatória capaz de revelar a existência de um núcleo normativo nas instituições e nas práticas realmente existentes. Ela intervém "na luta em torno da magnae chartae [constituição] em relação às matrizes transnacionais" $\mathrm{e}$ busca "desenvolver em cada caso direitos humanos e organizacionais específicos" ${ }^{\text {" }}$

Os direitos fundamentais ${ }^{75}$ (e aqui podemos compreender os direitos humanos) protegem o primado da diferenciação funcional da sociedade em face das tendências desdiferenciantes ${ }^{76}$, não mais apenas da política, mas agora, especificamente, dos sistemas sociais globais.

Com a emergência do direito global na sociedade moderna, marcada pela primazia da diferenciação funcional, as questões relativas a direitos humanos se tornaram especialmente sensíveis à afirmação do novo primado. A proteção aos direitos humanos tornou-se imprescindível para a manutenção da diferenciação funcional e da inclusão de toda a população mundial no sistema jurídico. ${ }^{77}$ Todavia, a diferenciação segmentária entre Estados nacionais no âmbito do sistema político da sociedade mundial inviabiliza o surgimento de uma "constituição mundial"78 capaz de proteger os direitos fundamentais para além do alcance estatal. Esse complexo desafio de uma sociedade profundamente fragmentada e reificada pela hipertrofia de determinadas racionalidades sistêmicas é enfrentado pela teoria crítica dos sistemas por meio daquilo que aqui se denomina de "resistência normativa" in praxis (de cunho crítico-emancipatório).

Essa resistência normativa da teoria crítica dos sistemas não está ligada a modelos procedimentais que priorizam o consenso universal ou a justificação racional, antes, ela se pauta nos "processos sociais de constitucionalização" (gesellschaftliche Konstitutionalisierungsprozesse) e na formação de "instituições permeáveis às demandas sociais" ${ }^{79}$ - trata-se aqui da socialização dos processos de criação do direito. Primeiramente os "processos sociais de constitucionalização", os quais precisam ser assegurados, estabilizados e tornados permanentes para que se façam efeti-

\footnotetext{
${ }^{71}$ FISCHER-LESCANO, 2013, p. 33 [2010, p. 176]. Acerca disso, ver também, LUHMANN, N. Die Politik der Gesellschaft. Frankfurt am Main: Suhrkamp, 2000. p. 215.

${ }^{72}$ Cf. TEUBNER, 2003, p. 9 e ss.

${ }^{73}$ MARX, K. El Capital: crítica de la economía política. México: Fondo de Cultura Económica, 1973. v. I. p. 43. Ver também FISCHER-LESCANO, 2013, p. 34 [2010, p. 175].

${ }^{74}$ FISCHER-LESCANO, 2013,'p. 34 [2010, p. 176]. Acerca disso, ver TEUBNER, 2012; NEVES, 2009. Para um estudo específico da constitucionalização no âmbito corporativo, ver esp. AMATO, Lucas F. Constitucionalização corporativa: direitos humanos fundamentais, economia e empresa. Curitiba: Juruá, 2014.

${ }^{75}$ Cf. TEUBNER, G. “The anonymous matrix: human rights violations by 'private' transnational actors”. The Modern Law Review. Malden, v. 69, n. 3, p. 327-346, 2006b. p. 342.

${ }^{76}$ Cf. LUHMANN, LUHMANN, N. Los derechos fundamentales como institución. México D.F.: Iteso/Universidad Iberoamericana, 2010 . p. 321.

${ }^{77}$ Cf. LUHMANN, 1993, p. 573 [2005, p. 651].

${ }^{78}$ Cf. LUHMANN, 1993, p. 582 [2005, p. 660].

${ }^{79}$ FISCHER-LESCANO, 2013, p. 35 [2010, p. 176]. Ver também TEUBNER, G. "Die Erblast". Zeitschrift für Rechtssoziologie, 29, Heft 1, p. 3-7, 2008. p. 3; TEUBNER, 2012; TEUBNER, G. The Project of Constitutional Sociology”. Transnational Legal Theory, Cambridge, 4, p. 44-58, 2013.
} 
vos. As constituições protegem os direitos fundamentais. Nesse sentido, no caso de dilatarmos seu alcance para todos os âmbitos sociais quanto possíveis, na forma de uma capilarização constitucional $^{80}$, tornar-se-ia possível blindar as esferas autônomas da sociedade dos impulsos hipertróficos e desdiferenciantes de determinadas racionalidades sociais e ao mesmo tempo autolimitar as esferas sociais constitucionalizadas.

Segundo Wiethölter, levar o conceito de autonomia sistêmica a sério significa compreender que a autodeterminação implica ao mesmo tempo a inevitabilidade de externalizações. As externalizações (nem sempre negativas) não se confundem com "determinações externas" (Fremd-Bestimmung), antes, podem ser consideradas como potenciais suportes em momentos nos quais a autoajuda (Selbsthilfe) sistêmica já não é mais possível. ${ }^{81}$ "Isso pode ser comparado com a assistência terapêutica ou suporte estrutural além do direito" ${ }^{82}$, ou seja, a ajuda externa é possível não como determinação jurídica de outras esferas sociais, mas sim como uma espécie de prestação jurídica à sociedade por meio de processos de constitucionalização que auxiliam na manutenção da diferenciação funcional da sociedade, combatendo a nova dialética do esclarecimento.

Os processos de constitucionalização seriam capazes de assegurar a existência de "espaços sociais de liberdade", tais como as "esferas espontâneas". As esferas espontâneas atuam em face das "esferas organizadas" presentes numa diversidade de sistemas sociais. ${ }^{83} \mathrm{~A}$ diferença entre esfera espontânea e esfera organizada, além de ser uma diferenciação interna dos próprios sistemas, é também, segundo Teubner, essencial para a diferenciação funcional da sociedade. A atuação da esfera espontânea barra as tendências reificantes da esfera organizada e da racionalidade sistêmica específica. Na economia, a diferença entre esfera espontânea e esfera organizada se manifesta na oposição entre os consumidores e as grandes corporações; na política essa diferença também aparece, mas na forma de contraposição entre governo e opinião pública. ${ }^{84}$

O equilíbrio entre o espontâneo e o organizado deve ser recalibrado, especialmente no sentido de impedir a dominação do último sobre o primeiro. A presença de uma esfera espontânea nos sistemas é essencial para a existência de maior responsividade sistêmica e abertura ecológica. Esse equilíbrio se torna possível graças à criação de mecanismos democráticos internos a cada âmbito sistêmico, capazes de potencializar a participação, a deliberação, a descentralização, entre outros modos de abertura.

A inovação dessa proposta está em sua abrangência, que não mais se limita ao âmbito territorial dos Estados nacionais, alçando agora a possibilidade de atingir setores sociais autônomos e transnacionalizados. Esses avanços já estavam presentes nos marcos das "constituições civis globais" de Teubner 85 e do "constitucionalismo societal" de Sciulli. ${ }^{86}$ Quando a teoria crítica dos sistemas fala em processos de constitucionalização da sociedade, ela está indo muito além do mero acoplamento estrutural entre sistema jurídico e sistema político. Ela busca demonstrar que os processos de constitucionalização podem emergir do contato do sistema jurídico com outros sistemas sociais, tais como a economia, a ciência, a saúde, dentre outros.

Os processos sociais de constitucionalização permitem ao sistema jurídico compensar o déficit do estabelecimento de estruturas normativas

\footnotetext{
${ }^{80}$ TEUBNER, 2012, p. 83-86.

${ }^{81}$ Cf. WIETHÖLTER, Rudolf. Zum Fortbildungsrecht der (richterlichen) Rechtsfortbildung: Fragen eines lesenden Recht-Fertigungslehrers. 3 Kritische Vierteljahreszeitschrift für Gesetzgebung und Rechtswissenschaft, Baden-Baden, p. 1-28, 1988. p. 27-28. Para conferir mais acerca do desenvolvimento desse programa por Wiethölter, ver esp. WIETHÖLTER, Rudolf. Justifications of a law of society. In: PEREZ, Oren; TEUBNER, Gunther (Ed.). Paradoxes and inconsistencies in the law. Oxford: Hart, 2005. p. 65 e ss. Fazendo uso da ideia de "assistência terapêutica" e "constitucionalização" em Wiethölter, ver esp. TEUBNER, 2012, p. 35.

${ }^{82}$ WIETHÖLTER, 1988, p. 28.

${ }^{83}$ Cf. TEUBNER, 2012, p. 88 e ss.

${ }^{84}$ Cf. TEUBNER, 2012, p. 89.

${ }^{85}$ Cf. TEUBNER, 2003. Ver também TEUBNER, Gunther. Regimes privados: direito neoespontâneo e constituições dualistas na sociedade mundial. In: RÜDIGER, Dorothee; MENDES, Rodrigo (Org.). Direito, sistema e policontexturalidade. Piracicaba: Unimep, 2005a; TEUBNER, 2005b.

${ }^{86}$ Cf. SCIULLI, David. Theory of societal constitutionalism: fundations of a non-marxist critical theory. New York: Cambridge University Press, 1992. p. 67.
} 
na sociedade moderna, na forma de um caminho que possibilita remediar os efeitos negativos do predomínio hipertrófico de racionalidades de sistemas prioritariamente compostos por estruturas cognitivas (economia, ciência, técnica). Ao mesmo tempo, esses processos buscam também repelir toda espécie de regresso desdiferenciante da sociedade, seja de ordem política ou religiosa, e ao mesmo tempo se levantam em face da expansividade dos processos de poder na sociedade mundial.

Complementarmente aos processos de constitucionalização, a resistência normativa proposta pela teoria crítica dos sistemas está baseada, também, na legislação da sociedade civil via processos de escandalização como a "colère publique mundial". ${ }^{87}$ Do mesmo modo, considera-se a possibilidade da tomada de decisões em situações deliberativas por meio da articulação entre as esferas espontânea e organizada. ${ }^{88} \mathrm{Em}$ suma, isso representaria o estabelecimento de processos de autorregulação social. Nas palavras de Fischer-Lescano, "trata-se da abertura das decisões estruturais da sociedade sobre processos democráticos por meio do desenvolvimento de direitos constitucionais da sociedade mundial que liberta o potencial da sociedade civil global para salvaguarda da autonomia". ${ }^{9}$ A grande pre- ocupação da teoria crítica dos sistemas é com a possibilidade da "regeneração das relações autônomas na sociedade mundial"; trata-se de procurar "romper com os padrões de estratificação das instituições sociais". ${ }^{90}$

Tiradas essas conclusões, ainda na esteira da teoria crítica dos sistemas, Fischer-Lescano observa a possibilidade de um paralelo entre o conceito de "responsividade social" (soziale Responsivität) dos sistemas e o conceito de mimesis da teoria crítica. ${ }^{91}$ Porém, diferentemente da teoria crítica da primeira geração da Escola de Frankfurt, a teoria crítica dos sistemas postula que não é apenas o sistema da arte que pode trabalhar como um "órgão da mimesis" (Organ der Mimesis)..${ }^{92}$ Segundo Fischer-Lescano:

As ordens mundiais dos sistemas sociais precisam adotar uma relação mimética com a realidade externa ao sistema. Deixar a transcendência aparecer na realidade, ou seja, a negação do existente na mimese do existente não é assim apenas tarefa da arte, mas de todos os sistemas sociais que têm de ser orientados de modo que 'o sujeito, em diferentes níveis de sua autonomia, possa colocar-se no outro, separado, mas também sem separar-se. ${ }^{93}$

Essa relação mimética "é uma reação à má irracionalidade do mundo racional enquanto administrado" 94 , em outras palavras, a mimesis é

\footnotetext{
${ }^{87}$ Cf. FISCHER-LESCANO, 2007, p. 443.

${ }^{88}$ Cf. FISCHER-LESCANO, 2013, p. 36 [2010, p. 176-177].

${ }^{89}$ Cf. FISCHER-LESCANO, 2013, p. 36 [2010, p. 177]. Ver também TEUBNER, Gunther. Fragmented foundations. In: DOBNER P.; LOUGHLIN, M. (Ed.). The twilight of constitutional law. Oxford: Hart, 2010. p. 327-341.

${ }^{90}$ FISCHER-LESCANO, 2013, p. 36 [2010, p. 177].

${ }_{91}$ Cf. FISCHER-LESCANO, 2013, p. 36 [2010, p. 177].

${ }^{92}$ Cf. FISCHER-LESCANO, 2013, p. 36 [2010, p. 177]. Na concepção de Adorno: "O comportamento mimético, posição perante a realidade aquém da oposição fixa de sujeito e objeto, é, graças à arte, órgão da mimese desde o tabu mimético, açambarcado pela aparência e, complementarmente à autonomia da forma, quase seu suporte. [...] se o comportamento mimético não imita alguma coisa, mas se faz semelhante a si mesmo, as obras de arte tomam a seu cargo o seu cumprimento. Na expressão, não imitam as emoções de indivíduos humanos, e sobretudo não as dos seus autores; ao definirem-se essencialmente deste modo são vítimas, justamente enquanto cópias, da objectivação, contra a qual resiste o impulso mimético. Na expressão artística, leva-se simultaneamente a cabo o juízo histórico sobre a mimese enquanto comportamento arcaico: a saber, praticada imediatamente, ela não é um conhecimento; o que se faz semelhante não se torna semelhante; a intervenção da malsucedida - tudo isso a exila para a arte que se comporta mimeticamente, da mesma maneira que ela absorve na objectivação desse impulso a crítica que lhe é feita. [Tradução nossa]".

No original: "Die mimetische Verhaltensweise, eine Stellung zur Realität diesseits der fixen Gegenübersetzung von Subjekt und Objekt, wird durch die Kunst, das Organ der Mimesis seit dem mimetischen Tabu, vom Schein ergriffen und, komplementär zur Autonomie der Form, geradezu dessen Träger. [...] Ahmt das mimetische Verhalten nicht etwas nach, sondern macht sich selbst gleich, so nehmen die Kunstwerke es auf sich, eben das zu vollziehen. Nicht imitieren sie im Ausdruck einzelmenschliche Regungen, vollends nicht die ihrer Autoren; wo sie dadurch wesentlich sich bestimmen, verfallen sie als Abbilder eben der Vergegenständlichung, gegen die der mimetische Impuls sich sträubt. Zugleich vollstreckt sich im künstlerischen Ausdruck das geschichtliche Urteil über Mimesis als ein archaisches Verhalten: daß diese, unmittelbar praktiziert, keine Erkenntnis ist; daß, was sich gleichmacht, nicht gleich wird; daß der Eingriff durch Mimesis mißlang - das verbannt sie ebenso in die Kunst, die mimetisch sich verhält, wie diese in der Objektivation jenes Impulses die Kritik an ihm absorbiert." (ADORNO, T. W. Teoria estética. Lisboa: Edições 70, 1982. p. 130-131 [Ästhetische Theorie. In: furt am Main: Suhrkamp, 1984, 7. p. 169-170]).

${ }_{93}$ FISCHER-LESCANO, 2013, p. 36 [2010, p. 177]. Nesse ponto, Fischer-Lescano cita diretamente Adorno no trecho final, cf. a versão original: "In ihr stellt das Subjekt, auf wechselnden Stufen seiner Autonomie, sich zu seinem Anderen, davon getrennt und doch nicht durchaus getrennt" (ADORNO, 1982, p. $68[1984,7$, p. 86]).

${ }^{94}$ ADORNO, 1982, p. 68 [1984, 7, p. 86].
} 
uma forma de reação interna à imanência reificada dos sistemas sociais fetichizados por suas próprias racionalidades.

Ao retirar a exclusividade da estética para a prática da resistência, a teoria crítica dos sistemas assegura essa possibilidade a todas as esferas sociais normativas, "preservando espaços de liberdade e espontaneidade e garantindo que prevaleçam sempre noções democráticas de organizações, instituições, grupos e redes sociais". ${ }^{95}$ Esse é o teor crítico-emancipatório da teoria, a resposta normativa da sociedade à hipertrofia de determinadas formas de racionalidades sistêmicas. Isso, ao mesmo tempo, representa a possibilidade de desreificação do sistema jurídico a partir da ideia de justiça, que dá ao sistema uma abertura ecológica, impelindo-o à transcendência e à constante dinâmica inovativa de suas próprias estruturas.

O direito, na teoria crítica dos sistemas, na forma de direito mimético, reage contra si (em face de sua própria racionalidade irracional) em favor de uma justiça autossubversiva (ecológica) e em oposição às tendências patológicas da sociedade mundial, lesivas aos espaços sociais de liberdade e às esferas espontâneas, buscando o auxílio da autolimitação dos sistemas sociais a partir dos constantes processos sociais de constitucionalização.

\section{CONCLUSÃO}

No âmbito jurídico, uma justiça que se autossubverte seria o ponto central da crítica imanente do direito. O sistema jurídico, quando reificado por sua própria imanência, torna-se autista e por isso cego ao ambiente, refletindo unicamente sua própria racionalidade universalizante, ou seja, sua própria "racionalidade irracional", na fórmula adorniana. $\mathrm{O}$ imperialismo da racionalidade jurídica cria novas formas de injustiças, as quais podem ser combatidas apenas pelo elemento transcendente do sistema jurídico: a justiça autossubversiva. A justiça autossubversiva é "a justiça do outro" (Lévinas/Derrida), da alteridade, do ambiente, que quebra o encanto do fechamento sistêmico e permite ao sistema trans- cender os limites internos de sua racionalidade. Trata-se aqui da justiça ecológica, tão próxima da problemática dos direitos fundamentais no sentido amplo descrito por Teubner em sua crítica às matrizes da sociedade global.

A crítica imanente do direito representa a libertação de seu "arcano" interno, capaz de identificar as discrepâncias internas do sistema e seus paradoxos, ou seja, não se trata mais de uma mera atitude conformista de um sistema jurídico sem "justiciabilidade"; agora é adicionado no sistema jurídico o "olhar maligno" e o ímpeto crítico-emancipatório diante do status quo, mediante a justiça autossubversiva.

$\mathrm{Na}$ teoria crítica dos sistemas o direito deixa de ser apenas o sistema imunológico da sociedade e passa a atuar como instrumento de práxis revolucionária (justiça autossubversiva), como apontado por Brunkhorst. Nesse sentido, os processos sociais de constitucionalização e a preservação dos espaços sociais de liberdade, tais como as esferas espontâneas, surgem como demandas essenciais que requerem o apoio do sistema jurídico.

Em suma, o principal escopo da teoria crítica dos sistemas é a "regeneração das relações autônomas da sociedade mundial". Nesse sentido, o papel desempenhado pelo sistema jurídico está em auxiliar na democratização dos sistemas sociais e na garantia da responsividade do sistema jurídico, de um modo terapêutico (Wiethölter). Como destacado por Fischer-Lescano, essa regeneração das "relações autônomas da sociedade mundial" só pode aperfeiçoar-se com os crescentes processos de constitucionalização das esferas sociais em conjunto com uma justiça autossubversiva, frutos de um sistema jurídico mais responsivo e com capacidade de transcendência. Formulando com o auxílio de um conceito adorniano, o direito concebido pela teoria crítica dos sistemas é um direito mimético que reage em face da imanência reificada e da fetichização provocada pela hipertrofia de sua racionalidade específica - assim, o direito na teoria crítica dos sistemas é um direito mais sensível ao ambiente, que dele se reaproxima através de um novo cará-

${ }^{95}$ FISCHER-LESCANO, 2013, p. 37 [2010, p. 177]. 
ter responsivo (ecológico).

\section{REFERÊNCIAS}

ADORNO, T. W. Ästhetische Theorie. In: Gesammelte Schriften. Band 7. Frankfurt am Main: Suhrkamp, 1984, 7. [Versão em português: ADORNO, T. W. Teoria estética. Lisboa: Edições 70, 1982].

.Kritik. In: Gesammelte Schriften. Band 10. Frankfurt am Main: Suhrkamp, 1984. p. $785-793.10$

- Philosophie der neuen Musik. In: . Gesammelte Schriften. Band 12. Frankfurt am Main: Suhrkamp, 1984. 12

Hegel: three studies. Cambridge: MIT, 1993. [ADORNO, T. W. Drei Studien zu Hegel. In: . Gesammelte Schriften. Band 5. Frankfurt am Main: Suhrkamp, 1984. 5]

Introdução à sociologia. São Paulo: UNESP, 2007.

Minima Moralia: reflexões a partir da vida lesada. Rio de Janeiro: Azougue, 2008. [ADORNO, T. W. Minima Moralia: Reflexionen aus dem beschädigten Leben. In: . Gesammelte Schriften. Band 4. Frankfurt am Main: Suhrkamp, 1984. 4]

Dialética Negativa. Rio de Janeiro: Zahar, 2009. [ADORNO, T. W. Negative Dialektik. In: Gesammelte Schriften. Band 6. Frankfurt am Main: Suhrkamp, 1984. 6] Versão alternativa: ADORNO, T. W. Negative Dialektik. Frankfurt am Main: Suhrkamp, 1975.

; HORKHEIMER, M. La sociedad: lecciones de sociología. Buenos Aires: Proteo, 1969.

AMATO, Lucas F. Constitucionalização Corporativa: direitos humanos fundamentais, economia e empresa. Curitiba: Juruá, 2014.

BACHUR, João Paulo. Inclusão e exclusão na teoria dos sistemas sociais: um balanço crítico.
BIB. São Paulo, n. 73 , p. $55-83,1^{\circ}$ semestre de 2012.

BACKER, Larry Catá. The structure of global law: fracture, fluidity, permeability and polycentricity. CPE Working Papers, n. 2012-7, Carlisle, Penn State Law, Research Paper n. 15, p. 102122, 2012.

BRUNKHORST, H. Solidarity: from civic friendship to a global level community. Cambridge: MIT Press, 2005.

Ilusões de factibilidade, declarações festivas e cantorias: sobre a relação entre evolução e revolução no Direito. Civitas. Porto Alegre, v. 9, n. 3, p. 440-458, 2009.

. Democracy under pressure: the return of the Dialectics of Enlightenment in the world society. Civitas. Porto Alegre, v. 10, n. 1, p. 153171, jan.-abr. 2010.

Rumo a uma nova ordem global: vinte anos após 1989 e além. RBCS, v. 26, n. 77, p. 2530 outubro 2011.

BUCKEL, Sonja . Zwischen Schutz und Maskerade: Kritik(en) des Rechts. Informationsbrief \# 102, Aufgabe 102, p. 11-23, august 2009. Rav Infobrief.

; FISCHER-LESCANO, Andreas. Reconsiderando Gramsci: hegemonia no direito global. Revista Direito GV, São Paulo, 5(2), p. 471-490, jul.-dez. 2009.

CAMPILONGO, Celso F. O direito na sociedade complexa. São Paulo: Max Limonad, 2000.

CÍCERO, Marcus Tullius. De Officiis. Translated by Walter Miller. Loeb edn. Cambridge: Harvard University Press, 1913.

DERRIDA, Jacques. Força de Lei: o fundamento místico da autoridade. São Paulo: Martins Fontes, 2007. 
ELMAUER, Douglas. O Direito na teoria crítica dos sistemas: da justiça autossubversiva à crítica imanente do direito. 2015. 316f. Dissertação (Mestrado em Direito) - Departamento de Filosofia e Teoria Geral do Direito da Faculdade de Direito da Universidade de São Paulo. São Paulo, SP, 2015.

FISCHER-LESCANO, Andreas. Ex facto ius oritur: procesos de escándalo y el Derecho Mundial emergente. DOXA - Cadernos de Filosofia del Derecho, v. 30. p. 435-450, 2007.

Systemtheorie als kritische Gesellschaftstheorie. In: AMSTUTZ, M.; FISCHER-LESCANO, A. (hrsg.). Kritische Systemtheorie: Zur Evolution einer normativen Theorie. Bielefeld: Transcript Verlag, 2013. p. 13-37. [Versão em português: FISCHER-LESCANO, Andreas. A teoria crítica dos sistemas da Escola de Frankfurt. Revista Novos Estudos, São Paulo, v. 86, p. 163-177, março 2010].

; TEUBNER, Gunther. Colisões de regimes - a busca vã por unidade jurídica na fragmentação do direito global. Revista Brasileira de Estudos Constitucionais - RBEC. Belo Horizonte, ano 6, n. 21, p.105-155, jan./mar. 2012. [Versão em inglês: TEUBNER; FISCHER-LESCANO. Regimme-collision. The vain search for legal unity in the fragmentation of global law. Michigan Journal of International Law. Michigan, v. 25, 2004].

FOUCAULT, Michel. O que é a crítica? 1978. p. 1-29. Disponível em: <www.filoesco.unb.br/foucault $>$. Acesso em: 12 jan. 2011.

FROMM, Erich. The sane society. London: Routledge, 2008.

GUERRA FILHO, Willis Santiago. Luhmann and Derrida: Immunology and Autopoiesis. In: LA COUR, Anders; PHILIPPOPOULOS-MIHALOPOULOS, Andreas. (Org.). Luhmann Observed: Radical Theoretical Encounters. Londres, 2013. p. 227-242.
HABERMAS, Jürgen. Teoría de la accion comunicativa. Buenos Aires: Taurus, 1999. 2. v.

HONNETH, Axel. Pathologies of reason: on the legacy of critical theory. New York: Columbia University Press, 2009.

HORKHEIMER, Max. Teoría tradicional y teoría crítica. In: (Org.). Teoría crítica. Buenos Aires: Amorrortu, 2003.

KJÆR, Poul. Law and Order within and Beyond National Configurations. 2010. Disponível em: <papers.ssrn.com/sol3/papers.cfm?abstract_ $\mathrm{id}=1687013>$. Acesso em: 12 jan. 2013.

LUHMANN, N. Die Weltgesellschaft. Soziologische Aufklärung 2: Aufsätze zur Theorie der Gesellschaft. Opladen:Westdeutscher Verlag, p. 51-71, 1975.

.Evolution und Geschichte.Soziologische Aufklärung 2: Aufsätze zur Theorie der Gesellschaft. Opladen: Westdeutscher Verlag, p. 150-69, 1976.

Ausdifferenzierung des Rechts: Beiträge zur Rechtssoziologie und Rechtstheorie. Frankfurt: Suhrkamp, 1981.

- Sociologia do direito. Rio de Janeiro: Tempo Brasileiro, 1983. 2. v.

Das Recht der Gesellschaft. Suhrkamp: Frankfurt am Main, 1993.

Inklusion und Exklusion. Soziologische Aufklärung 6: Die Soziologie und der Menschen. Opladen: Westdeutscher Verlag, p. 237-264, 1994.

Jenseits von Barbarei. Gesellschaftsstruktur und Semantik. Studien zur Wissenssoziologie der modernen Gesellschaft. Frankfurt: Suhrkamp, v. 4, p. 138-150, 1995.

Inclusion y exclusion. Complejidad y Modernidad: de la unidad a la diferencia. Madri: Trotta. 1998. p. 167-195. 
Die Politik der Gesellschaft. Frankfurt am Main: Suhrkamp, 2000.

El derecho de la sociedad. Ciudad de México: Herder, 2005.

La sociedad de la sociedad. Ciudad de México: Herder, 2007.

Los derechos fundamentales como institución. México D.F.: Iteso/Universidad Iberoamericana, 2010.

MARX, K. (1973) El Capital: crítica de la economía política. México: Fondo de Cultura Económica, $1973.3 \mathrm{v}$.

MENKE, Christoph.Subjektive Rechte: Zur Paradoxie der Form. Zeitschrift für Rechtssoziologie, Berlin, v. 29, 2008.

NEVES, Marcelo. "Pesquisa interdisciplinar no Brasil: o paradoxo da interdisciplinariedade." In: Crítica à dogmática: dos bancos acadêmicos à prática dos tribunais. Porto Alegre: Instituto de hermenêutica Jurídica, 2005. p. 207-214.

Transconstitucionalismo. [Tese apresentada ao concurso de provas e títulos para provimento do cargo de Professor Titular na área de direito constitucional, junto ao Departamento de Direito do Estado da Faculdade de Direito da Universidade de São Paulo]. São Paulo, 2009.

. Niklas Luhmann: Eu vejo o que tu não vês. In: ALMEIDA, Jorge de; BADER, Wolfgang (Org.). Pensamento alemão no século XX: grandes protagonistas e recepção da obra no Brasil. São Paulo: Cosac Naify; Instituto Goethe de São Paulo, 2013. p. 257-273.

PASCHUKANIS, Evgeni. A teoria geral do direito e o marxismo. Coimbra: Centelha, 1977.

PHILIPPOPOULOS-MIHALOPOULOS, Andreas. Critical autopoiesis and the materiality of Law. International Journal for Semiotics of Law. Berlin, Springer Science, p. 1-19, 2013.
SANTOS, Boaventura Sousa. Por que é tão difícil construir uma teoria crítica? Revista crítica das ciências sociais, Coimbra, n. 54, jun. 1999.

SCIULLI, David. Theory of societal constitutionalism: fundations of a non-marxist critical theory. New York: Cambridge University Press, 1992.

STICHWEH, Rudolf. Inklusion/Exklusion, funktionale Differenzierung und die Theorie der Weltgesellschaft. Soziale Systeme, Stuttgart, (1997) Heft 3. p. 123-136.

On the genesis of world society: innovations and mechanisms. 2000. Disponível em: <http://www.uni-bielefeld.de/(en)/soz/iw/pdf/ stichweh_2.pdf $>$. Acesso em: 20 ago. 2012.

TEUBNER, Gunther. A Bukowina Global sobre a emergência de um pluralismo jurídico transnacional. Impulso, Piracicaba, v. 14, n. 33, p. 9-31, 2003.

. Regimes privados: direito neoespontâneo e constituições dualistas na sociedade mundial. In: RÜDIGER, Dorothee; MENDES, Rodrigo (Org.). Direito, sistema e policontexturalidade. Piracicaba: Unimep, 2005a.

La constitucionalización de la sociedad global. In: Carlos Gómez-Jara Díez (Ed.) El derecho como sistema autopoiético de la sociedad global. Lima: ARA Editores, 2005b. p. 69-111.

. Dealing with paradoxes of law: Derrida, Luhmann, Wiethölter. In: ; PEREZ, O. Paradoxes and inconsistencies in the law. Portland: Hart Publishing, 2006a. p. 41-64.

. The anonymous matrix: human rights violations by 'private' transnational actors. The Modern Law Review. Malden, vol. 69, n. 3, p. 327-346, 2006 b.

. Die Erblast. Zeitschrift für Rechtssoziologie, Stuttgart, 29, Heft 1, 2008, p. 3-7.

Self-subversive justice: contingency or 
transcendence formula of Law? 2009. p. 1-22. Disponível em: <www.uni-frankfurt.de/>. Acesso em: 20 out. 2010. [Versão em português: TEUBNER, Gunther. Justiça autosubversiva: fórmula de contingência ou de transcendência do Direito? Revista Eletrônica do Curso de Direito - PUC Minas Serro [Online], 0.4, 17-54, 2011b.].

. Fragmented foundations. In: DOBNER P.; LOUGHLIN, M. (Ed.) The twilight of constitutional law. Oxford: Hart, 2010. p. 327-341.

A constitutional moment? The logics of 'hitting bottom'. In: KJÆR, Poul, TEUBNER, Gunther, FEBBRAJO, Alberto (Ed.). Financial crisis in constitutional perspective: the dark side of functional differentiation. Oxford: Hart, 2011a. p. 9-51.

. Constitutional fragments: societal constitutionalism and globalization. Oxford: Oxford University Press, 2012.

The Project of Constitutional Sociology Transnational Legal Theory, Cambridige, 4, p. 44-58, 2013.

; GRABER, Christoph B. Art and money: constitutional rights in the private sphere? Oxford Journal of Legal Studies. Oxford, v. 18, n. 1, p. 61-73, 1998.

VILLAS BÔAS FILHO, Orlando. Da ilusão à fórmula de contingência: a justiça em Hans Kelsen e Niklas Luhmann. In: PISSARA, Maria Constança Peres; FABBRINI, Ricardo Nascimento (Coord.). Direito e filosofia: a noção de justiça na história da filosofia. São Paulo: Atlas, 2007. p. 129-150.

WIETHÖLTER, Rudolf. Zum Fortbildungsrecht der (richterlichen) Rechtsfortbildung: Fragen eines lesenden Recht-Fertigungslehrers". 3 Kritische Vierteljahreszeitschrift für Gesetzgebung und Rechtswissenschaft, Baden-Baden, p. 1-28, 1988.

Just-ifications of a Law of Society. In:

PEREZ, Oren; TEUBNER, Gunther (Ed.). $\mathrm{Pa}$ - radoxes and inconsistencies in the law. Oxford: Hart, 2005. p. 65-77.

ŽIŽEK, Slavoj. Unsere Trägheit ist die größte Gefahr“. Der Spiegel, Heft 12, 14. p. 130-134, März 2015.

ZUMBANSEN, Peer. Transnational law. In: SMITS, Jan (Ed.). Encyclopedia of comparative law. Northampton: Edward Elgar Publishing, 2006. p. 738-754.

Recebido: 11/11/2015

Aprovado: 21/12/2015 